\title{
Identifying Subalpine Fir (Abies lasiocarpa) Attacked by the Balsam Woolly Adelgid (Adelges piceae) Using Spectral Measurements of the Foliage
}

\author{
Stephen P. Cook, ${ }^{1}$ Karen S. Humes, ${ }^{2}$ Ryan Hruska, ${ }^{3}$ Grant Fraley, \\ and Christopher J. Williams ${ }^{5}$ \\ ${ }^{1}$ Department of Plant, Soil and Entomological Sciences, University of Idaho, Moscow, ID 83844-2339, USA \\ ${ }^{2}$ Geography Department, University of Idaho, Moscow, ID 83844-3021, USA \\ ${ }^{3}$ Ecological Science Division, Idaho National Laboratory, P.O. Box 1625, Idaho Falls, ID 83415-2213, USA \\ ${ }^{4}$ Department of Geography, San Diego State University, San Diego, CA 92182, USA \\ ${ }^{5}$ Department of Statistics, University of Idaho, Moscow, ID 83844-1104, USA \\ Correspondence should be addressed to Stephen P. Cook, stephenc@uidaho.edu
}

Received 26 April 2010; Accepted 9 August 2010

Academic Editor: Robin Reich

Copyright ( $) 2010$ Stephen P. Cook et al. This is an open access article distributed under the Creative Commons Attribution License, which permits unrestricted use, distribution, and reproduction in any medium, provided the original work is properly cited.

\begin{abstract}
Balsam woolly adelgid is an invasive pest of firs in the United States. Aerial surveys are conducted for detection of adelgid infestations but other remotely sensed data may also be useful. Our objective was to determine if high spectral resolution, branchlevel data can be used to distinguish infested from noninfested trees. Stepwise discriminant analysis yielded a three-variable model (the red-green index and two narrow-bands (one at $670 \mathrm{~nm}$ and the other at $1912 \mathrm{~nm}$ )) that classified infested versus non-infested trees with $94 \%$ accuracy compared with the $83 \%$ accuracy obtained with a single-variable model. The response of trees in narrow spectral bands was integrated across wavebands to simulate measurements from the multispectral SPOT5-HRVIR sensor. Stepwise discriminant analysis again yielded a three-variable model (simple ratio, the SPOT5-HRVIR band in the SWIR region and NDVI) with similar accuracy (93\%) at discriminating infested from non-infested trees compared with the $83 \%$ accuracy obtained with a single-variable model.
\end{abstract}

\section{Introduction}

Balsam woolly adelgid, Adelges piceae (Ratzeburg) (Hemiptera: Adelgidae), is an invasive pest of true firs in the United States. The adelgid is native to the fir forests of central Europe and was introduced into North America around 1900 [1]. The life cycle of balsam woolly adelgid consists of the egg, three larval instars, and the adult female (see [2] for a more thorough description). The only life stage capable of movement is the first instar larva (termed the crawler) that, upon locating a suitable feeding site, inserts her stylet into the bark and transforms (without molting) into a neosistens, after which the insect is permanently attached to the host tree. As she feeds, the female secretes a dense waxy covering that ultimately covers the entire insect.
The crawler stage does not have wings, and between-tree dispersal is a passive process in which individuals are carried primarily by wind. The adult female produces as many as 248 eggs that are oviposited within the woolly mass which acts to protect all of the life stages except the crawler [2].

All native, North American true firs (Abies) show some degree of susceptibility to the balsam woolly adelgid and four species (subalpine fir, A. lasiocarpa, Fraser fir, A. fraseri, balsam fir, A. balsamea, and Pacific silver fir, A. amabilis) are highly susceptible to infestation [3]. The insect is currently established on susceptible hosts in both the eastern and western United States where it is responsible for significant levels of mortality within some stands. In north-central Idaho, the adelgid is primarily found infesting and causing mortality to subalpine fir [4]. 
Infestation of North American firs by the adelgid results in anatomical and structural changes within host tissues that may be the result of salivary excretions from the insect's stylet during feeding [2]. Physically, the xylem tissue of infested trees has higher concentrations of ray tissue $[5,6]$, thickened cell walls, and shorter tracheids [7] that have encrusted pit membranes that more closely resemble the pit membranes associated with heartwood [8]. There is a corresponding reduction in water flow in infested trees [5] that puts the tree into a state of physiological drought that in turn reduces photosynthesis and respiration [9]. Damage to the host tree is related to both the size of the tree and the intensity of the infestation. Balsam woolly adelgid infestations in the crown of a tree usually result in gouting (characterized by node and/or bud swelling with a decrease in new growth of the stem and foliage) of the outer branches [3]. Over time, the crown thins and the foliage fades in color. Balsam woolly adelgid infestations also occur on the stems of trees. In North America, these stem infestations usually kill native firs within 6 years [2]. We hypothesized that foliar symptoms of infestations such as thinning and color change could be detected using remotely sensed data.

Active resistance mechanisms by a host tree to insect attack can be energy intense to maintain and utilize. The decline that occurs within a host following infestation by adelgids may be categorized as a continuous summary decline as characterized for balsam fir infested with balsam woolly adelgid [10] and for eastern hemlock infested with hemlock woolly adelgid [11]. Changes in foliar chemistry that are related to tree stress can be manifested in measurable spectral changes within the foliage (see [12] for a review of spectral changes of trees infested by the mountain pine beetle, Dendroctonus ponderosae). The Wulder et al. [12] review suggests that remotely sensed data is useful for detecting infestations of mountain pine beetle damage and suggests that future experimental work be conducted at several spatial scales.

Both the spatial (i.e., pixel size) and spectral (width of the individual spectral wavebands over which plant response is measured) resolutions of the data, as well as the overall wavelength range examined (some sensors operate through the middle infrared region, some do not) and signal-to-noise ratio of individual bands in a sensor can influence the ability to detect infested trees with a specific sensor. Multispectral remotely sensed data types tend to have fewer, wider spectral wavebands and are operationally available from satellite platforms over a wide range of spatial resolutions $(<1 \mathrm{~m}$ to $30 \mathrm{~m}$ ). Landscape-scale hyperspectral data sensors are less widely available and typically have a large number of very narrow wavebands. Because most hyperspectral data sets are acquired from aircraft platforms, these data tend to have spatial resolution on the order of 5 to $20 \mathrm{~m}$. Handheld spectroradiometers for use on the ground operate in wavelengths similar to those in airborne hyperspectral sensors and have similar or greater numbers of narrow spectral bands. There have been several prior studies related to the detection and classification of trees infested with invasive adelgids. Luther \& Carroll [10] examined several foliar indices for assessing overall tree vigor in balsam fir using

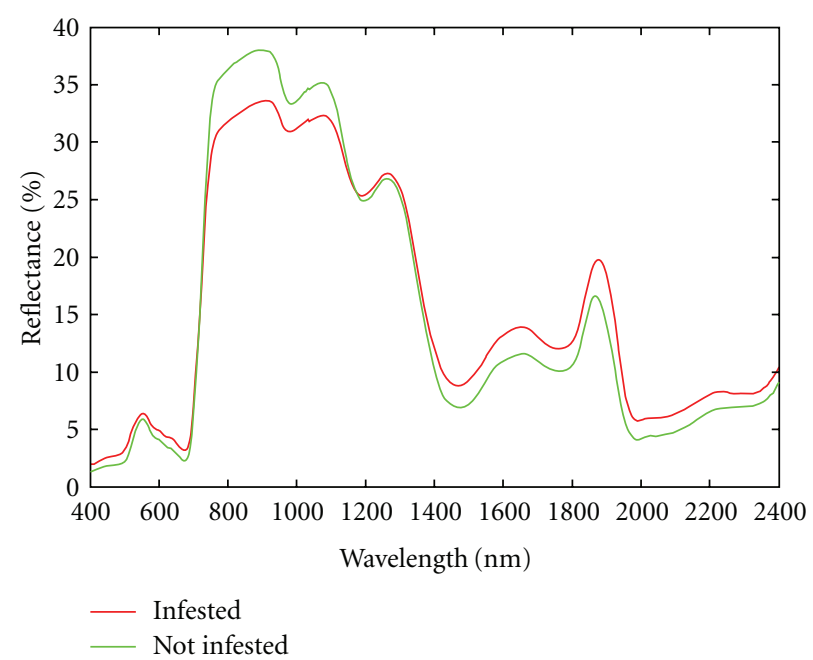

Figure 1: Mean spectral signatures of foliage from subalpine fir trees in the intermountain west measured using a ground-based spectroradiometer for trees that were not infested $(n=84)$ or infested $(n=122)$ with the balsam woolly adelgid.

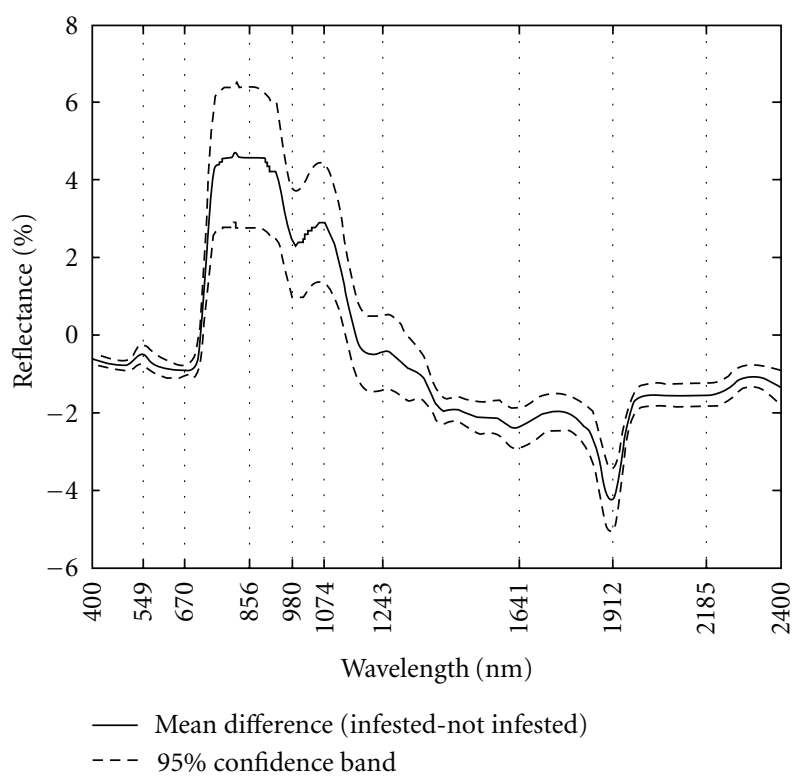

FIGURE 2: Difference in the mean spectral response (solid line) of subalpine fir trees that were not infested or infested with the balsam woolly adelgid. Dashed lines represent the $95 \%$ confidence intervals around the mean. Dotted vertical lines represent the narrow wavebands selected for use in the stepwise discriminant analysis.

spectral reflectance data and reported that foliar reflectance decreased with decreasing vigor in most of the wave bands but was most significant in the wave bands between 500 and $740 \mathrm{~nm}$. These authors conducted their work in the laboratory using a fixed position spectroradiometer. Adelgid infestation was not specifically investigated, but infestation of fir with balsam woolly adelgid does result in decreased tree vigor. At the landscape scale, hemlock stands were similarly 
assessed and analyzed for health status using multispectral Landsat Thematic Mapper (TM) data [13]. These authors reported that the best overall accuracy for classifying stand health based on hemlock woolly adelgid infestation was obtained using the Modified Soil Adjusted Vegetation Index2. Pontius et al. [11] used hyperspectral data to examine the abundance and early decline of hemlock infested with hemlock woolly adelgid with over $80 \%$ accuracy. They used a chlorophyll sensitive waveband (R683 nm), coupled with a water band index (R970/R900) to predict hemlock decline. These authors suggest that wavelengths in the visible portion of the spectrum may be useful in assessing early stages of decline of hemlock infested with hemlock woolly adelgid.

As moderate and high spatial resolution multispectral data become more widely available via sensors such as SPOT5-HRVIR (10 $\mathrm{m}$ and $20 \mathrm{~m}$ spatial resolution), IKONOS (4 m spatial resolution), and Quickbird (2.44 m spatial resolution), it is especially important to define both the spatial and spectral resolutions at which insect infestations and other stressors can or cannot be detected. The objective of the current project was to investigate the spectral resolution required to differentiate infested and noninfested trees at the branch level. Branch-level spectral responses acquired with a ground-based handheld spectroradiometer were evaluated on the ability to distinguish subalpine firs that were infested with balsam woolly adelgid from noninfested subalpine firs. Narrow-band spectral data were also integrated across the appropriate spectral wavebands to simulate the branch-level response of one commonly available multispectral satellite sensor (SPOT5-HRVIR). These band-equivalent responses were used to evaluate whether the more coarse spectral resolution would still allow discrimination at the branch level. While other sensors are available and similar analyses could be conducted to evaluate them, the SPOT5-HRVIR sensor was selected for evaluation because it offers the potential for relatively broad area coverage at moderate spatial resolution $(10 \mathrm{~m}$ pixel size in the visible and nearinfrared portions of the spectrum; $20 \mathrm{~m}$ pixel size in the shortwave infrared).

\section{Materials and Methods}

2.1. Field Sampling Locations and Procedures. Field work was conducted during July and August of 2001 and 2002 at seven locations in northern Idaho and eastern Washington (Table 1). The field sites ranged from frost pockets in relatively low elevation drainages to higher elevation mountain forests. The low elevation sites were predominantly mixed conifer forests containing pine, true firs, and Douglas-fir while the higher elevation sites were characterized as sprucefir or fir-hemlock forests. A total of 206 mature subalpine fir trees were sampled. Of the total, 122 trees were infested with balsam woolly adelgid and 84 were not infested based upon physical presence of the insect. Adelgid-infested trees all had bole infestations, there were no insects present on the actual foliage of infested trees. Heavily infested trees that were presumed to be older infestations had gouting present on the limbs as well as foliage that appeared to be thinner

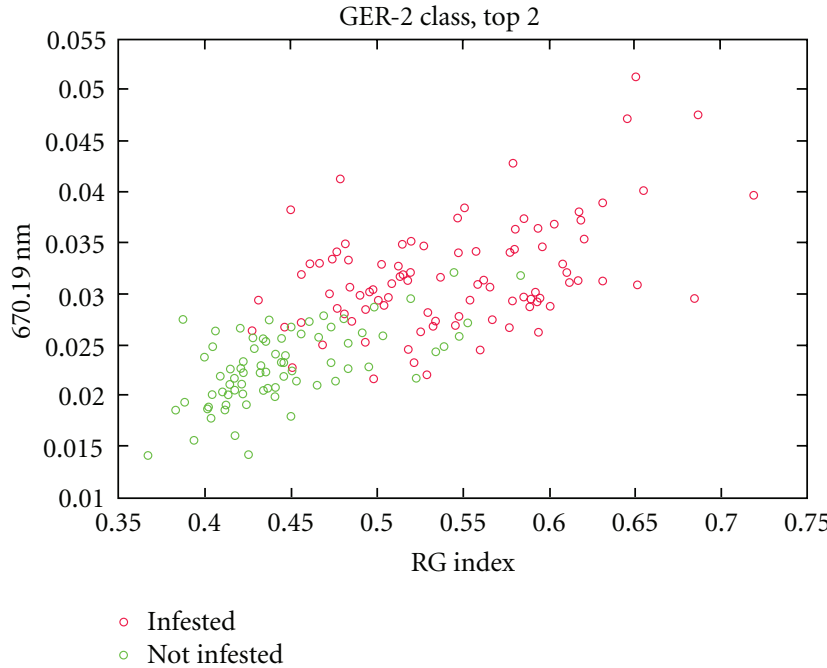

FIGURE 3: Values for the red green index (ratio of bands centered at $660 \mathrm{~nm}$ and $549 \mathrm{~nm}$, resp.) and percent reflectance in a narrow band centered at $670 \mathrm{~nm}$ for individual trees infested or not infested with balsam woolly adelgid. The two variables were selected using a stepwise discriminant analysis procedure for distinguishing infested from noninfested trees.

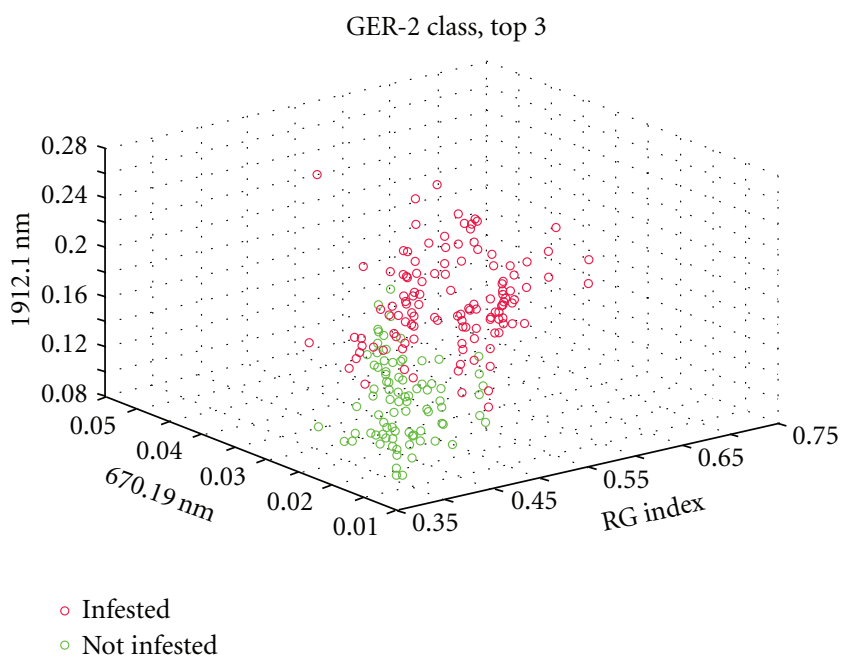

FIGURE 4: Values for the red green index (ratio of bands centered at $660 \mathrm{~nm}$ and $549 \mathrm{~nm}$, resp.), percent reflectance in a narrow band centered at $670 \mathrm{~nm}$, and percent reflectance in the narrow band centered at $1912 \mathrm{~nm}$ for individual trees infested or not infested with balsam woolly adelgid. The three variables were selected using a stepwise discriminant analysis procedure for distinguishing infested from noninfested trees.

and less vibrant in color. These trees were less abundant than trees that were lightly infested or not infested with the adelgid. Because we could not accurately determine how long an infestation had been present on a tree, all infested trees were grouped into a single category for the current analysis.

Branch-level spectral radiance data were collected under field conditions using a Geophysical Environmental Research Corp. (Millbrook, NY), 2600 spectroradiometer with a $3^{\circ}$ 
TABLE 1: Sampling locations, years, and number of trees per location in northern Idaho and eastern Washington from which spectral data of mature subalpine fir trees were collected.

\begin{tabular}{|c|c|c|c|c|c|}
\hline Year & Site & Easting $^{\mathrm{a}}$ & Northing $^{\mathrm{a}}$ & Elevation $(\mathrm{m})$ & $N$ \\
\hline \multirow{2}{*}{2001} & Freezeout Ridge & 571403 & 5207488 & 1797 & 20 \\
\hline & Flat Creek & 518688 & 5187696 & 898 & 28 \\
\hline \multirow{7}{*}{2002} & Santain Road & 606207 & 5075184 & 1098 & 21 \\
\hline & Red River & 629498 & 5063073 & 1332 & 27 \\
\hline & Hobo Pass & 565419 & 5213883 & 1399 & 26 \\
\hline & Homestead Creek & 578780 & 5219219 & 1630 & 28 \\
\hline & Misery Spring & 462899 & 5107177 & 1878 & 28 \\
\hline & Freezeout Ridge & & & & 15 \\
\hline & Flat Creek & & & & 13 \\
\hline Total & & & & & 206 \\
\hline
\end{tabular}

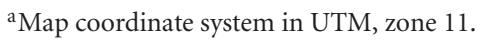

TABLE 2: Narrow spectral wavebands available for selection in the stepwise discriminant analysis.

\begin{tabular}{ll}
\hline $\begin{array}{l}\text { Waveband center } \\
(\mathrm{nm})\end{array}$ & Spectral location \\
\hline$\rho_{549}$ & Green reflectance maximum \\
$\rho_{670}$ & Red absorption maximum \\
$\rho_{856}$ & Peak in the spectral response difference \\
$\rho_{980}$ & $\mathrm{H}_{2} \mathrm{O}$ absorption well \\
$\rho_{1074}$ & NIR reflectance peak, peak in the spectral \\
& response difference \\
$\rho_{1243}$ & $\begin{array}{l}\mathrm{H}_{2} \mathrm{O} \text { absorption well edge, peak in the } \\
\text { spectral response difference }\end{array}$ \\
$\rho_{1641}$ & SWIR reflectance peak, peak in the \\
& spectral response difference \\
$\rho_{1912}$ & $\mathrm{H}_{2} \mathrm{O}$ absorption well edge, peak in the \\
& spectral response difference \\
$\rho_{2185}$ & SWIR reflectance peak
\end{tabular}

fore optic. The GER2600 collects spectral data over 616 channels from 350 to $2500 \mathrm{~nm}$ using two detector arrays. The silicon detector array provides a bandwidth of $1.5 \mathrm{~nm}$ in the spectral range from 350 to $1050 \mathrm{~nm}$ (visible and near-infrared). The $\mathrm{PbS}$ detector array provides a bandwidth of $11.5 \mathrm{~nm}$ in the spectral range from 1050 to $2500 \mathrm{~nm}$ (shortwave infrared). Measurements were collected between 10:00 and 13:00 hours local time under clear to mostly sunny skies, resulting in sun elevation angles between 64.7 and 41.9 degrees. Care was taken to avoid measurements that could be affected by cloud shadow. Five branches, each from a different aspect within the canopy, were excised from each tree using a pruning pole. Because trees were experiencing bole infestations that impact the entire tree, not individual branches, no attempt was made to select individual branches based on the presence of the insect on any particular branch. Branches were randomly selected, had diameters of approximately $1.0 \mathrm{~cm}$, and no branches were from overlapping areas within the canopy. Branches
TABLE 3: Narrow waveband spectral indices available for selection in the stepwise discriminant analysis.

\begin{tabular}{lc}
\hline Spectral index & Formula \\
\hline Red/Green Ratio (R/G) & $\frac{\rho_{659}}{\rho_{549}}$ \\
Simple Ratio (SR) & $\frac{\rho_{659}}{\rho_{859}}$ \\
Normalized Difference & $\frac{\rho_{859}-\rho_{659}}{\rho_{859}+\rho_{659}}$ \\
Vegetation Index (NDVI) & $\frac{\rho_{894}}{\rho_{972}}$ \\
Water Index (WI) & $\frac{\rho_{856}-\rho_{1243}}{\rho_{856}+\rho_{1243}}$ \\
Normalized Difference & \\
Water Index (NDWI) & $\frac{\rho_{856}-\rho_{1641}}{\rho_{856}+\rho_{1641}}$ \\
Infrared Index (II) &
\end{tabular}

were excised from both sunlit and shaded portions of the crown. The branches were transported to a fully sunlit area and measured within 20 minutes of excision. The five branches were stacked in a pile on a sampling table (1.2 by $2 \mathrm{~m}$ dimensions) that was painted with Krylon UltraFlat black paint with the radiometer mounted $30 \mathrm{~cm}$ above the sample. For each tree, the branches were restacked and measured with the spectroradiometer 5 times. Caution was used to insure that both current-year needles and previous-year needles was included in the field of view of the sensor (approximate diameter $=2.5 \mathrm{~cm}$ ) and branches were rotated between measurements. The average of these 5 measurements for each tree were used as the response for a given tree. To control for different light conditions and adjust radiance data to reflectance, a white reference panel with known hemispherical reflectance (Spectron SRT99-05, Labsphere, Inc., North Sutton, New Hampshire) was measured between the spectral measurements obtained for each tree. 
TABLE 4: Spectral wavebands of the SPOT5-HRVIR sensor.

\begin{tabular}{lc}
\hline SPOT5-HRVIR & \\
spectral waveband & Wavelength \\
\hline Panchromatic & $480-710 \mathrm{~nm}$ \\
Green & $500-590 \mathrm{~nm}$ \\
Red & $610-680 \mathrm{~nm}$ \\
Near infrared (NIR) & $790-890 \mathrm{~nm}$ \\
Shortwave infrared (SWIR) & $1580-1750 \mathrm{~nm}$ \\
\hline
\end{tabular}

2.2. Spectral Data Processing. The branch-level spectral radiance data were converted to percent reflectance using the following equation:

$$
\rho_{\text {target }}=\left(\frac{\mathrm{L}_{\text {target }}}{\mathrm{L}_{\text {plate }}}\right)^{*} \rho_{\text {plate }},
$$

where:

$$
\begin{aligned}
\rho_{\text {target }} & =\text { Reflectance of target foliage }, \\
\rho_{\text {plate }} & =\text { Reflectance of reference plate }, \\
\mathrm{L}_{\text {target }} & =\text { Radiance of target foliage }, \\
\mathrm{L}_{\text {plate }} & =\text { Radiance of reference plate },
\end{aligned}
$$

The known hemispherical reflectance of the reference plate was provided by Labsphere Inc., North Sutton, New Hampshire. These values were then interpolated for each band center acquired by the GER2600. One measurement per tree was calculated by averaging the 5 spectral measurements for each tree. The resulting reflectance spectra were smoothed to remove any channel-to-channel noise introduced by the sensor using a weighted-average moving-window approach [14]. The moving-window used 5 bands for the visible and near infrared portion of the spectrum and 3 bands for the shortwave infrared portion of the spectrum.

2.3. Statistical Analysis. Differences in spectral reflectance values were compared between adelgid-infested subalpine firs and noninfested trees using Students' $t$-tests on the narrow band data [15]. Nine individual bands located in various regions of the spectral signature were selected for use in the discriminant analysis (Table 2). In addition, six spectral indices that combine information from two or more spectral bands (and that may be important in evaluating vegetation status) were calculated for each tree (Table 3 ).

The nine individual bands and six spectral indices were used in a stepwise discriminant analysis procedure to examine the separation between adelgid-infested and noninfested subalpine fir. Discriminant analysis [15] was performed using $67 \%$ of the data that were randomly selected for training $(n=138)$. The performance of the 1-, 2-, and 3-variable models selected based upon improving $\mathrm{R}^{2}$ values by the stepwise analysis procedure was assessed using improvement in correct classification of trees in two different data sets: (1) an independent validation using only the remaining $33 \%$ of the data $(n=68$ trees $)$ not used for
TABLE 5: Classification results (\%age of individual trees that were correctly classified as infested or not infested with the adelgid) obtained from the discriminant analysis procedure. Results in the validation samples column were generated by applying the discriminant function developed from a randomly selected training data set to the remaining $33 \%$ of the observations $(n=68)$. Results in the all samples column were generated by applying the discriminant function developed using the entire data set of 206 trees sampled during the study.

\begin{tabular}{lcc}
\hline & \multicolumn{2}{c}{ Correctly classified (\%) } \\
Model parameters $^{1}$ & Validation samples & All samples \\
\hline R/G & 88 & 83 \\
R/G; Red & 96 & 91 \\
R/G; Red; SWIR & 91 & 94 \\
\hline
\end{tabular}

${ }^{1}$ The model parameters are $\mathrm{R} / \mathrm{G}=\mathrm{Red} /$ Green ratio where Red represents a single narrow band centered at $660 \mathrm{~nm}$ and Green represents a single narrow band centered at $549 \mathrm{~nm}$; Red = an individual narrow band centered at $670 \mathrm{~nm}$ and in the red spectral region; SWIR = an individual narrow band centered at $1912 \mathrm{~nm}$ in the shortwave infrared region.

TABle 6: Classification results (\%age of individual trees that were correctly classified as infested or not infested with the adelgid) obtained from the discriminant analysis procedure for the SPOT5-HRVIR Band Equivalent Reflectance (BER). Results in the validation samples column were generated by applying the discriminant function developed from a randomly selected training data set to the remaining $33 \%$ of the observations $(n=68)$. Results in the all samples column were generated by applying the discriminant function developed using the entire data set of 206 trees sampled during the study.

\begin{tabular}{lcc}
\hline & \multicolumn{2}{c}{ Correctly classified (\%) } \\
Model parameters $^{1}$ & Validation samples & All samples \\
\hline SR & 84 & 83 \\
SR; SWIR & 84 & 91 \\
SR; SWIR; NDVI & 86 & 93 \\
\hline
\end{tabular}

${ }^{1}$ The model parameters are SR $=($ Red/NIR $)$ where Red represents the SPOT- 5 BER response in the red region, NIR represents the SPOT- 5 BER response band in the near infrared region; SWIR $=$ the SPOT-5 BER response in the shortwave infrared region; NDVI $=(\mathrm{NIR}-\mathrm{Red}) /(\mathrm{NIR}+$ Red).

training and (2) correct classification for data from all 206 trees (i.e., both training and validation data together).

2.4. SPOT Band Equivalent Reflectance Calculations. The individual narrow-bands from the spectroradiometer that correspond to the wider spectral bands available from the SPOT5-HRVIR satellite sensor were integrated across wavelengths to generate the Band Equivalent Reflectance (BER) for each of the SPOT5-HRVIR bands (Table 4) for each tree. Specifically, the BER values were computed by numerically convolving the spectral response in the appropriate narrow wavebands with the filter response function for each waveband of the SPOT5-HRVIR sensor. The Band Equivalent Reflectance (BER) in these five bands plus four indices (II, NDVI, SR, and R/G (Table 3)) were used in a second stepwise discriminant analysis procedure [15] to examine the potential utility of satellite-based multispectral sensors 


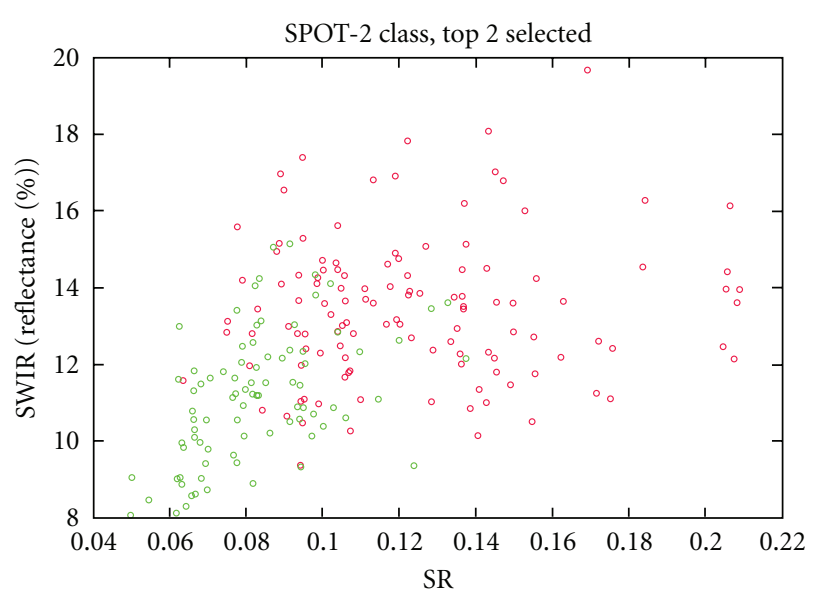

Figure 5: Values for the simple ratio and percent reflectance in the SWIR for individual trees infested or not infested with balsam woolly adelgid. Reflectances and band ratios were computed by integrating the narrow band data to the SPOT5-HRVIR band equivalent reflectance. The two variables were selected using a stepwise discriminant analysis procedure for distinguishing infested from noninfested trees.

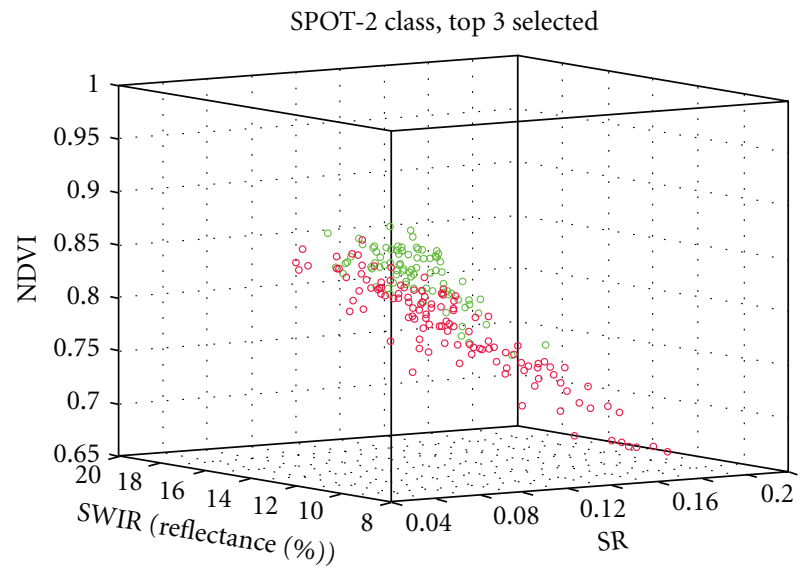

FIGURE 6: Values for simple ratio, the percent reflectance in the SWIR and the NDVI for individual trees infested or not infested with balsam woolly adelgid. Reflectances and band ratios were computed by integrating the narrow band data to the SPOT5HRVIR band equivalent reflectance. The three variables were selected using a stepwise discriminant analysis procedure for distinguishing infested from noninfested trees.

for the remote detection of adelgid-infested subalpine fir. The best 1-, 2-, and 3-variable models were examined in a similar manner as those developed with the narrow band reflectances and indices.

\section{Results and Discussion}

There were differences in the spectral features of foliage from subalpine fir trees that were infested with balsam woolly adelgid when compared with noninfested trees (Figure 1). All of the individual narrow band measurements were significantly different $(P \leq .05)$ when comparing infested with noninfested trees except for a very small area of the spectral range near $700 \mathrm{~nm}$ and the area of the range from approximately $1150 \mathrm{~nm}$ to $1300 \mathrm{~nm}$ (Figure 2). Changes in foliar chemistry that are related to tree stress can be manifested in measurable spectral changes within the foliage. Much of the literature with regard to another tree-killing insect, mountain pine beetle (Dendroctonus ponderosae Hopkins (Coleoptera: Curculionidae)), is reviewed by [12] and describes studies that have been published related to detection of beetle infestations. The decline that occurs within a host following infestation by adelgids is similar and can be categorized into various levels as characterized for hemlock [11] and balsam fir [10]. Given the reduction in water flow [5] and crown structure [3] that occurs in balsam woolly adelgid-infested trees, changes in the overall foliar reflectance values across the spectral signature are likely. The area around $700 \mathrm{~nm}$ is a chlorophyll absorption well while the area from 1150 to 1300 typically responds to leaf water content [16]. The spectral region from 535 to $700 \mathrm{~nm}$ has been reported to be among the most sensitive to stress [17], and changes in the red edge have been associated with plant stress (i.e., [17-19]). Further, changes in leaf water content can cause significant changes in the spectral response of plants in the shortwave infrared region of the spectrum with a decrease in relative water content increasing the reflectance measured in the 1300-2500 $\mathrm{nm}$ range $[20,21]$

Based upon the stepwise discriminant analysis procedure, the subalpine firs infested with balsam woolly adelgid could be reliably distinguished from the noninfested trees (over $80 \%$ accuracy when tested with the validation data set) using a single variable model with the red-green index (Table 5). Model accuracy was improved to $91 \%-93 \%$ when the red-green index was used in combination with one band from the red region $(670 \mathrm{~nm})$ (Figure 3 ) or two bands (the one at $670 \mathrm{~nm}$ and another in the shortwave infrared region at $1912 \mathrm{~nm}$ ) (Figure 4). The combination of indices and bands that were selected through the stepwise discriminant analysis relys on spectral regions (green, red and SWIR) that should be related to stress. Heavy attack by insects on conifer hosts typically results in the foliage fading from green to red. The foliage from the infested trees that we sampled ranged from being slightly faded but still green to a greenish gray in color. No trees with extensive reddening of the foliage were included in our samples. However, the fading of the foliage is probably what is being captured by the red band and by the $R / G$ index which is simply a ratio of reflectance of two narrow bands, one in the red region and one in the green region. Changes in the SWIR spectral region are frequently associated with water stress of vegetation and infestation with balsam woolly adelgid reducing water flow and resulting in the tree being in a state of physiological drought $[5,9]$. The use of narrow-band, hyperspectral data has also been employed to identify stands of hemlock in the eastern United States that appear to be less vigorous and more susceptible to the hemlock woolly adelgid [11].

While hyperspectral data can provide much information, multispectral data such as that provided by the SPOT5HRVIR sensor are more readily available and tend to be 
less expensive to obtain. To simulate SPOT5-HRVIR data, we combined the individual narrow bands that correspond to the wide bands yielded by the SPOT5-HRVIR sensor (Table 4). When the individual narrow band data were combined to simulate these multispectral bands, infested trees could be distinguished from noninfested trees with $80 \%$ accuracy using a single variable model that used only the ratio of near infra-red to red spectral measurements (the simple ratio index, SR) (Table 6). The overall accuracy was increased to $83 \%$ correct using a two-variable model consisting of the simple ratio index and the short wave infrared band (SR + the SWIR band) (Figure 5) and further increased to $86 \%$ correctness using a three-variable model that included the addition of the normalized difference vegetation index along with the prior two measurements (SR + SWIR + NDVI) (Figure 6). As with the model produced using narrow band data, the simulated SPOT5-HRVIR parameters that were selected in the stepwise discriminant analysis procedure rely heavily upon bands in spectral regions that are associated with plant stress (green, red, NIR, and SWIR).

Our analyses suggest that infestations of balsam woolly adelgid may be detected using remotely sensed spectral data. However, it should be noted that trees were classified based upon presence or absence of the insect, not severity or length of infestation time. Early detections of infestations could result in more effective management of this invasive pest but our data is not sufficient to determine the length of time an infestation must be present to ensure the correct classification of infested trees. Also, our direct measurement of spectral features was conducted on branchlevel data. Successful discrimination between infested and noninfested trees at the branch scale provides necessary but not sufficient indication that discrimination is possible at the canopy scale. The successful discrimination of infested and noninfested trees at the canopy scale depends on a number of factors, including the spatial resolution of canopy-scale data, stand density and age, and the presence of other stressing agents. A coarser spatial resolution could result in multiple tree canopies occurring within individual pixels which could obscure the evaluation of individual trees. Similarly, increased stand density could result in multiple trees occupying the same pixels. Changes that may occur in the spectral measurements of foliage on subalpine fir trees as they age or are subjected to other potential stresses such as drought were not investigated. In addition, balsam woolly adelgid may infest an individual tree for years prior to causing tree mortality. If the observed changes across the spectral range occur gradually and in a predictable manner, it may be possible to detect infestations prior to when visible changes occur in the foliage of the infested tree. However, adelgids are not the only causal agents of stress in subalpine fir and tree response to these other stressors should be investigated.

\section{Acknowledgments}

The work was supported in part by the University of Idaho and by grants from the NSF-EPSCoR program and the USDA-Forest Service Special Technology Development program. The authors thank Stephani Sandoval, Kendra Schotzko, and Emily Heward for assistance with the collection of field data.

\section{References}

[1] R. E. Balsch, "Studies of the balsam woolly aphid, Adelges piceae (Ratz.) and its effects on balsam fir, Abies, (L.) Mill," Publication 897, p. 76, Canadian Department of Agriculture, 1952.

[2] F. P. Hain, "The balsam woolly adelgid in North America," in Dynamics of Forest Insect Populations, A. A. Berryman, Ed., pp. 89-109, Plenum Press, New York, NY, USA, 1988.

[3] R. G. Mitchell, "Infestation characteristics of the balsam woolly aphid in the Pacific Northwest," USDA Forest Service, Research Paper PNW-35, 1966.

[4] R. L. Livingston, J. E. Dewey, D. P. Beckman, and L. E. Stipe, "Distribution of the balsam woolly adelgid in Idaho," Western Journal of Applied Forestry, vol. 15, pp. 227-231, 2000.

[5] R. G. Mitchell, "Abnormal ray tissue in three true firs infested by balsam woolly aphid," Forest Science, vol. 13, pp. 327-332, 1967.

[6] F. H. Smith, "Effects of balsam woolly aphid (Adelges piceae) infestation on cambial activity in Abies grandis," American Journal of Botany, vol. 54, pp. 1215-1223, 1967.

[7] A. H. Doerksen and R. G. Mitchell, "Effects of the balsam woolly aphid upon wood anatomy of some western true firs," Forest Science, vol. 11, pp. 181-188, 1965.

[8] G. S. Puritch and R. P.C. Johnson, "Effects of infestation by the balsam woolly aphid, Adelges piceae (Ratz.) on the ultrastructure of bodered-pit membranes of grand fir, Abies grandis (Doug.) lindl," Journal of Experimental Botany, vol. 22, no. 4, pp. 953-958, 1971.

[9] G. S. Puritch, "Effects of water stress on photosynthesis, respiration, and transpiration of four Abies speices," Canadian Journal of Forest Research, vol. 3, pp. 293-298, 1973.

[10] J. E. Luther and A. L. Carroll, "Development of an index of balsam fir vigor by foliar spectral reflectance," Remote Sensing of Environment, vol. 69, no. 3, pp. 241-252, 1999.

[11] J. Pontius, R. Hallett, and M. Martin, "Using AVIRIS to assess hemlock abundance and early decline in the Catskills, New York," Remote Sensing of Environment, vol. 97, no. 2, pp. 163173, 2005.

[12] M. A. Wulder, C. C. Dymond, J. C. White, D. G. Leckie, and A. L. Carroll, "Surveying mountain pine beetle damage of forests: a review of remote sensing opportunities," Forest Ecology and Management, vol. 221, no. 1-3, pp. 27-41, 2006.

[13] L. R. Bonneau, K. S. Shields, and D. L. Civco, "Using satellite images to classify and analyze the health of hemlock forests infested by the hemlock woolly adelgid," Biological Invasions, vol. 1, no. 2-3, pp. 255-267, 1999.

[14] P. Gong, P. Ruilianp, and Y. Bin, "Conifer species recognition: an exploratory analysis of in situ hyperspectral data," Remote Sensing of Environment, vol. 62, no. 2, pp. 189-200, 1997.

[15] SAS Institute, PROC User's Manual, SAS Institute, Cary, NC, USA, 7th edition, 2002.

[16] J. R. Jensen, Introductory Digital Image Processing: A Remote Sensing Perspective, Prentice Hall, Upper Saddle River, NJ, USA, 3rd edition, 2005.

[17] G. A. Carter and D. R. Young, "Foliar spectral reflectance and plant stress on a barrier island," International Journal of Plant Sciences, vol. 154, no. 2, pp. 298-305, 1993. 
[18] J. E. Vogelmann, B. N. Rock, and D. M. Moss, "Red edge spectral measurements from sugar maple leaves," International Journal of Remote Sensing, vol. 14, no. 8, pp. 1563-1575, 1993.

[19] F. Boochs, G. Kupfer, K. Dockter, and W. Kuhbauch, "Shape of the red edge as vitality indicator for plants," International Journal of Remote Sensing, vol. 11, no. 10, pp. 1741-1753, 1990.

[20] G. A. Carter, "Primary and secondary effects on water content on the spectral reflectance of leaves," American Journal of Botany, vol. 78, no. 7, pp. 916-924, 1991.

[21] E. R. Hunt Jr. and B. N. Rock, "Detection of changes in leaf water content using near-and middle-infrared reflectances," Remote Sensing of Environment, vol. 30, no. 1, pp. 43-54, 1989. 

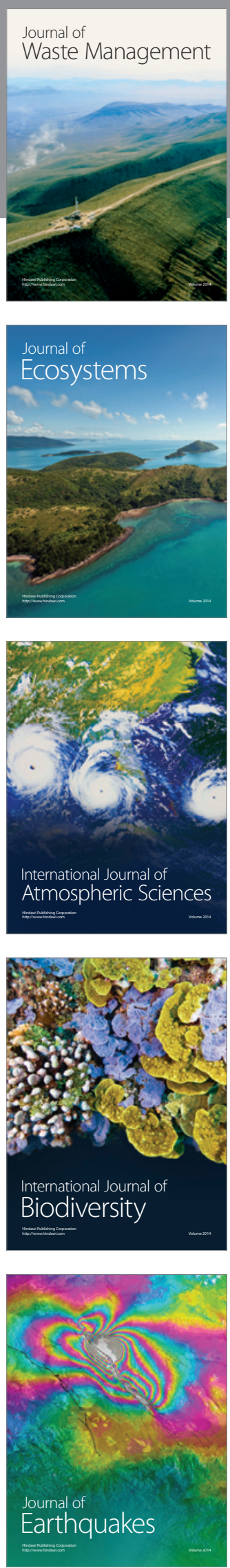
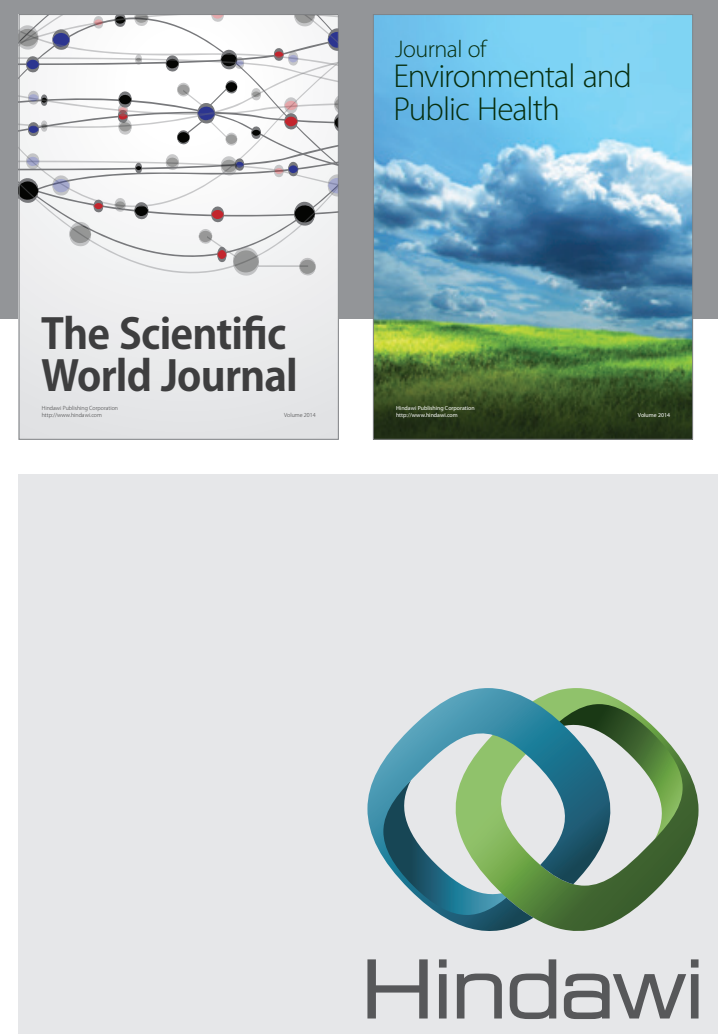

Submit your manuscripts at

http://www.hindawi.com
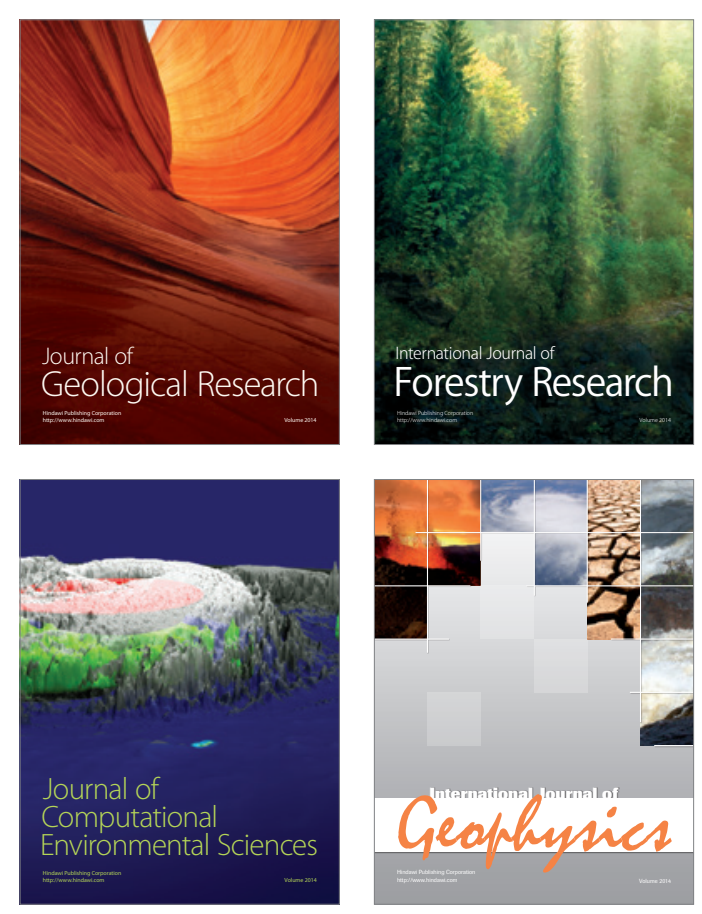
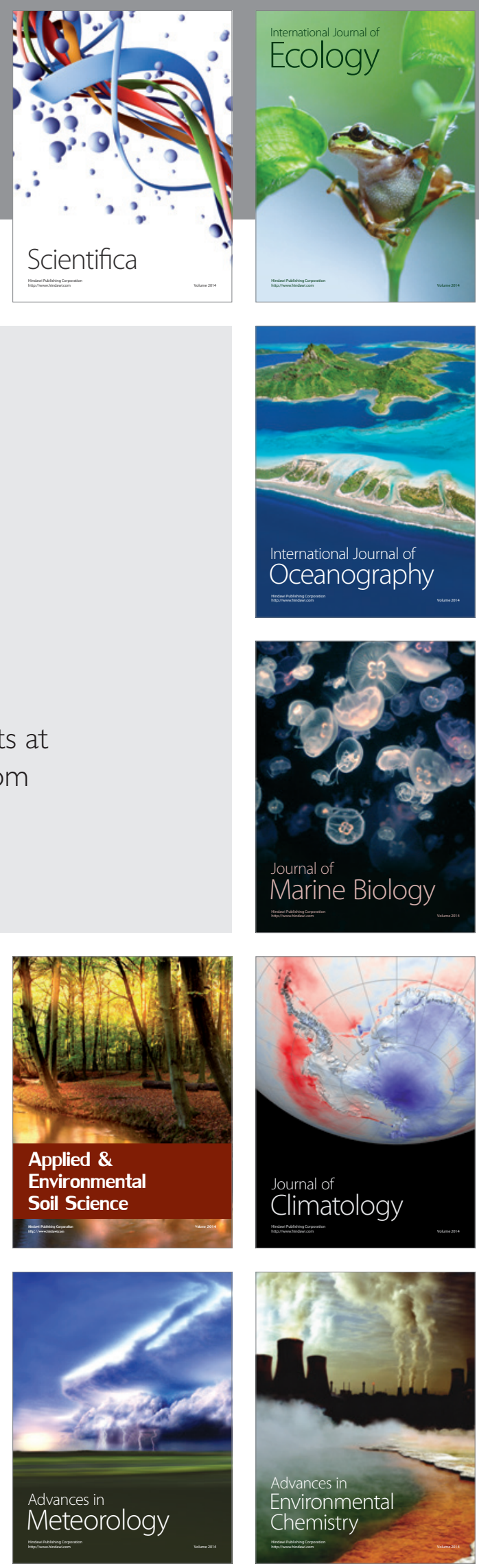